\title{
Early individual electronic identification of sea bass using RFID microtags: A first example of early phenotyping of sex-related growth
}

\author{
Sébastien Ferrari ${ }^{\mathrm{a}, \mathrm{b}}$, Béatrice Chatain ${ }^{\mathrm{b}, \mathrm{c}}$, Xavier Cousin $^{\mathrm{a}, \mathrm{d}}$, Didier Leguay $^{\mathrm{a}}$, Alain Vergnet ${ }^{\mathrm{c}}$, \\ Marie-Odile Vidal ${ }^{c}$, Marc Vandeputte ${ }^{c, e}$, Marie-Laure Bégout ${ }^{a, *}$
}

\author{
a Ifremer, Place Gaby Coll, BP 7, 17137 L'Houmeau, France \\ b UMR 110 INTREPID, Ifremer Cirad, 34000 Montpellier, France \\ ${ }^{c}$ Ifremer, Chemin de Maguelone, 34250 Palavas-Les-Flots, France. \\ d INRA LPGP, Campus de Beaulieu, 35042 Rennes, France \\ e INRA UMR 1313 GABI, F-78350 Jouy-en-Josas, France \\ *: Corresponding author : Marie-Laure Bégout, email address : Marie.Laure.Begout@ifremer.fr
}

\begin{abstract}
:
Although individual electronic tagging using PIT (Passive Integrated Transponder) tags is well established, it is mainly used for fish $>60 \mathrm{~mm}$ in length. Since electronic tagging is an ideal identification method, we used RFID (Radio Frequency Identification) microtags $(6 \mathrm{~mm}$ in length, $1 \mathrm{~mm}$ in diameter, $10 \mathrm{mg}$ in mass) to characterize individual fish from the early stages of their development and throughout their lifecycles. We used sea bass, Dicentrarchus labrax, (105 day-old fish weighing between 100 and $1100 \mathrm{mg}$ ) and studied the effects of intra-coelomic tagging in half the population using different endpoints including survival and tag reading, growth over 6 months and swimming responses. Dead fish were counted daily, biometric data were collected at 21 to 28 days intervals and fish were sexed at the end of the experiment. Behavioral swimming responses following a sudden dark challenge were evaluated after the first three biometric measurements (immediately after tagging, and then 21 and 42 days later). After 6 months, mean survival was $69 \%$, the smallest surviving fish weighed $197 \mathrm{mg}$ at tagging, and success in tag reading was $79 \%$ for the size class $300-400 \mathrm{mg}$ after 63 days. No negative effects were observed on growth and most deaths occurred within 15 days after tagging with a first peak after 5 days but that did not particularly affect the smallest individuals. Differences in swimming responses were detected between tagged fish and untagged controls immediately after the surgical procedure with tagged fish swimming more than controls for 45 minutes. However, after 21 days, the tagged fish swam less than the untagged controls after being placed in the observation tank for $1 \mathrm{~h} 45$. At 42 days post-tagging, no further differences were observed. Overall, results suggested that the tagging method was suitable for fish as small as $400 \mathrm{mg}$ and $36 \mathrm{~mm}$ in total length. This type of early tagging method is invaluable for the longitudinal monitoring of individual biological traits (e.g. growth) or for repeated assays with the same individual at distinct time points (e.g. behavior studies). We used it for a first evaluation of early growth differentiation between sexes and demonstrated a $31 \%$ mass gain difference in females that was visible as soon as the fish reached 105 days old. This confirms the potential of the method for the selection of early-expressed character traits which could lead to rearing cost savings for the aquaculture research field.
\end{abstract}

Keywords : Tagging effects ; swimming behavior ; sexual dimorphism ; Dicentrarchus labrax 


\section{Introduction}

The ability to recognize individuals within a large population of similar-sized congeners has long been regarded as useful, notably for fisheries research (e.g., growth rate estimations), ecological investigations (e.g., migration) and population dynamics studies. It is also useful in experiments when one needs to identify specific lines that have no external phenotypes (e.g., mutant or transgenic lines) or to monitor the same individuals over a long period of time (e.g., multiple challenges in behavioral analysis, monitoring of individual growth or spawning Cousin et al., 2012). Passive Integrated Transponder (PIT) tagging (Prentice et. al., 1984) is suitable for the identification of individuals and does not entail repeated handling. It has become a widely used tool for the identification of large numbers of individuals (Gibbons and Andrews, 2004). The tags also enable a degree of remote monitoring of fish passage or presence at key sites (Armstrong et. al., 1996, Brännäs and Alanärä, 1993, 1994, Prentice et. al. 1990a), of risk-taking behavior (Millot et al., 2009), of hypoxia tolerance (Laursen et al., 2011) and of a lot of other behavioral traits. In aquaculture, fish are usually tagged at an average mass of $10 \mathrm{~g}$ with PIT tags being implanted in the dorsal musculature or coelomic cavities of the fish. The PIT tag represents a small percentage of the body mass of the fish and has very little effect on their physiology but is not suitable for fish below $60 \mathrm{~mm}$ (for 12 mm long PIT tag, Baras et al., 2000).

However, because many biological phenomena emerge early in life or depend intimately on the conditions experienced at the early stages of life, it is often necessary and important to individually tag fish as young as possible (Baras et al., 1999). Not many effective solutions are available for smaller animals and the situation is further complicated for fish due to the medium in which they live and the presence of skin/scales, which makes the use of external tagging methods such as conventional painting difficult. Other non electronic tagging methods exist such as coded wire tags (CWTs) and visible implant elastomer (VIE), they have rarely been used in fish below $60 \mathrm{~mm}$ (Champigneulle et al. 1987) and they necessitate extensive manipulation to be read (Brennan et al. 2005, Bégout et al. 2012). 
The RFID (Radio Frequency Identification) electronic microtag, which has been used to document behavior in insects (ants, Moreau et al., 2011 and bees, Decourtye et al., 2011) has very recently been developed. The glass microtags, which are smaller than ordinary PIT tags, appear to be the best way to tag individuals at an early size/age, as successfully shown by Cousin et al. (2012) in zebrafish. Glass microtags have a very low mass ( $10 \mathrm{mg}$ ), an unlimited lifetime, can be associated with billions of individual codes, and can be applied to a broad sample of individuals. As reading uses a frequency in the $\mathrm{MHz}$ range (13.56 MHz), they can be coupled with a conventional PIT tag (in $\mathrm{kHz}$ ) at a later stage without interference. However, physiological and behavioral responses to a given method of tagging may vary depending on the species (Summerfelt and Smith, 1990, Winter, 1983) and studies on the effect of tagging are always strongly encouraged (Baras et al., 2000). New types of tags and fish species and/or development stages require validation before being used and detection and application methods should minimize or eliminate biases that may arise from changes in fish behavior, mortality, or biological functions. However, only a few studies have documented the feasibility of implementation of PIT tags in the coelomic cavity of small juveniles and they mostly involved salmonids (Brännäs and Alanärä, 1993, Ombredanne et. al., 1998, Peterson et. al., 1994, Prentice et. al. 1990b, Navarro et al., 2006). There is also no evidence that standard tagging procedures, which rely on the use of syringe injectors (Bergensen et. al. 1994, Prentice et. al. 1990b), are suitable for small fish juveniles (smaller than $1 \mathrm{~g}$ in mean body mass). Moreover, few studies have documented the relationship between tagging procedures and changes in fish behavior including swimming performances (Bégout et al. 2012, Cousin et al, 2012, Montoya et al., 2012).

The European sea bass (Dicentrarchus labrax, L.) is a high commercial value marine teleost. Its average aquaculture production worldwide from 2007 to nowadays is about 125.000 tons year $^{-1}$ (Tveteras and Nystoyl, 2011). Although the European sea bass is a key species for the Mediterranean aquaculture industry, its production is associated with a relevant drawback: the progeny sex ratio is highly skewed to males $(75-95 \%$, reviewed in 
Vandeputte et al., 2007) whereas males present earlier sexual maturation and lower growth (about $20-30 \%$ ) compared to females. The male-biased sex ratio of cultured populations is therefore a serious management issue for producers which require solving. Although the sex determinism system in European sea bass is to a large extent unknown (Piferrer et al., 2005), two main features may be distinguished, i.e. a lack of sex chromosomes and environmental sex determinism (ESD). Environmental sex determinism implies that the sex of a specimen is not fixed at conception but is influenced by environmental conditions during its early life (Vandeputte et al, 2007). Sexual differentiation is reached after a long period of time, i.e. about 130 days post-fertilization and after, as has been demonstrated by Saillant et al. (2003). This labile period therefore includes the early stage during which specimens develop their individual growth trajectories and gaining knowledge on this sensitive phase is of utmost importance. Furthermore, in the context of growing awareness of fish welfare associated with the development of genetic selection, one can imagine that methods enabling early behavioral or physiological phenotypic selection will be highly sought after.

The work described in this paper was carried out in two steps: the first experiment was a pilot study to evaluate the suitability of coelomic tagging with RFID glass microtag (Nonatec $\AA$ ) on 50 tagged fish with mean body weight of $840 \pm 20 \mathrm{mg}$ over 118 days. The purpose of the second experiment was to study the effects of tagging with RFID glass microtag over 184 days but starting on smallest fish (mean body weight of $590 \pm 22 \mathrm{mg}$ ) and with higher numbers ( $\mathrm{N}=188$ tagged fish). For the second experiment, besides growth, we also monitored the effect of tagging on baseline locomotion and photo motor responses to sudden dark challenge in tagged juvenile sea bass compared to untagged controls. We finally used this experiment to gain knowledge on early growth trajectory in seabass juveniles in relation to sex.

\section{Equipment and method}

\subsection{Origin of the fish and experimental structure:}

Experiment 1 (Exp. 1) 
Juvenile European sea bass were hatched and reared at Aquastream [Morbihan, Ploemeur, France]. They were 87 days when they arrived at our facility and they were allowed to recover from transport during 9 days. They were then reared in a $450 \mathrm{I}$ tank according to seabass rearing standard (Chatain 1994) using a recirculating system with a flow rate of $4 \mathrm{~m}^{3}$ per hour and water was renewed at a rate of $10 \%$ per day. The water temperature was maintained at $20.2 \pm 1.5^{\circ} \mathrm{C}$ and oxygenation at above $80 \%$ saturation in the water-outlet; salinity was $35.3 \pm 3.3$. The light regime was $13: 11 \mathrm{~L} / \mathrm{D}$ (light switched on at 09:00) with gradual twilight transition periods lasting 30 minutes. The fish were handfed upon arrival until the end of the experiment (commercial diet Le Gouessant (France) containing $45 \%$ crude protein and $20 \%$ lipids according to the manufacturer). Pellet size was gradually increased according to fish body mass. Fish were tagged when they were 96 days old with a mean body mass of $840 \pm 20 \mathrm{mg}$ (mean $\pm \mathrm{SD}$ ) for a min-max range in total length of $31 \mathrm{~mm}$ $41 \mathrm{~mm}$. The experiment took place over 118 days with 100 fish (50 tagged / 50 untagged controls) kept in one common garden tank. The aim of this experiment was to assess the feasibility of tagging juvenile seabass from 96 days post hatch (dph).

\section{Experiment 2 (Exp. 2)}

Juvenile European sea bass were hatched and reared at the aquaculture experimental research station of Ifremer in Palavas-les-Flots (Hérault, France). The fish were 105 days old at the start of the experiment (i.e. at tagging) and weighed between 100 and $1100 \mathrm{mg}$ (with a mean body mass of $590 \pm 22 \mathrm{mg}$ (mean \pm SD) for a min-max range in total length of $27-$ $53 \mathrm{~mm}$. They were reared according to seabass rearing standard (Chatain 1994) in a $1 \mathrm{~m}^{3}$ circular tank equipped with a flow-through system and supplied with seawater. The flow rate in the tanks was $1.6 \mathrm{~m}^{3}$ per hour, the temperature of the water was maintained at $22.4 \pm 2.1^{\circ} \mathrm{C}$, oxygenation was above $80 \%$ of saturation in the water-outlet, and salinity was $36.3 \pm 0.3$. The light regime was $15 \mathrm{~L} / \mathrm{D}$ (light switched on at 09:00). The fish were handfed during their early life and then were fed using self-feeders from 90 dph with the same commercial diet as described above. Pellet size was gradually increased according to the 
body mass of the fish. The experiment took place over 184 days with 389 fish (188 tagged / 201 untagged controls) kept in one common garden tank. The aim of this experiment was to assess tagging effects on growth, mortality and behavior of seabass tagged at $105 \mathrm{dph}$; and to provide the first insights on early individual phenotypic differentiation of sex-related growth in sea bass.

\subsection{Anesthesia and tagging procedure}

The two experiments were conducted following approval of the Animal Care Committee of France under the official license of M.-L. Bégout (17-010). A $10 \%$ stock solution of Ethyl-paminobenzoate (Benzocaine, E1501, Sigma, St Louis, MO, USA) was prepared by dissolving $100 \mathrm{~g}$ of Benzocaine in $1 \mathrm{I}$ of $100 \%$ ethanol. The anesthetic solution consisted of $325 \mu \mathrm{l}$ of stock solution dissolved in $1 \mathrm{I}$ of seawater. For tagging procedure, see Cousin et al. 2012 (JEB071829 Supplementary Material for a video). Briefly, intra-coelomic implantation was performed by piercing a hole in the abdominal cavity on the left side of the fish using a 22 gauge needle. Care was taken to pierce only the body wall muscle and not to insert the needle too far into the cavity so as to avoid damaging any organs. A microtag (Lutronics, Nonatec RFID, Lutronic International, Rodange, Luxembourg, www.nonatec.net; size $1 \mathrm{~mm} x$ $6 \mathrm{~mm}$; mass $10 \mathrm{mg}$; frequency: $13.56 \mathrm{MHz}$ ) was then transferred from the $70 \%$ ethanol to sterile saline solution $\left(9 \mathrm{~g} \mathrm{I}^{-1} \mathrm{NaCl}\right)$ for rinsing, picked up with Dumont No. 3 forceps, and introduced into the abdominal cavity through the hole made earlier, and pushed in until it was fully inserted. The whole procedure was routinely performed within $30 \mathrm{~s}$, and care was taken to limit the time the fish were kept out of the water to improve experimental success (tagging was done on batches of about 10 fish to minimize anesthesia duration to less than 5-6 min). The fish were then transferred to a tank of clean sea water for recovery from anesthesia and handling and allowed to rest for 10 - 15 minutes before being returned to their rearing tank. Control fish received the same treatment (anesthesia and biometric measurements out of water) except for the hole and the tag insertion. All control and microtagged fish were tagged with conventional PIT tags when they reached 164 dph in Exp. 1 and 197 dph in Exp.2. This 
was done to prevent loss of their identity and to enable correct sex assignment in Exp. 2 because we anticipated a lower reading success of microtags due to an important fish growth combined with a low detection range $(1-2 \mathrm{~cm})$.

\subsection{Survival, growth monitoring and early sex effects:}

Biometric measurements were made at $96 \mathrm{dph}, 122 \mathrm{dph}, 143 \mathrm{dph}, 164 \mathrm{dph}, 185 \mathrm{dph}$, $206 \mathrm{dph}$ and $258 \mathrm{dph}$ for Exp. 1 and at $105 \mathrm{dph}, 125 \mathrm{dph}, 147 \mathrm{dph}, 169 \mathrm{dph}, 197 \mathrm{dph}$, $226 \mathrm{dph}, 273 \mathrm{dph}$ and $289 \mathrm{dph}$ for Exp. 2. For each biometric measurement, the fish were fasted the preceding day, anesthetized as described above, measured for mass (to the nearest $\mathrm{mg}$ ) and standard length (to the nearest $\mathrm{mm}$ ) and then placed in sea water for recovering before being returned to their tank. Note that in Exp. 2, length measurements for untagged control were not done at $105 \mathrm{dph}$. During the biometric measurements, the microtags were read using the RFID reader connected to a computer, and the corresponding masses and lengths were recorded on a spreadsheet. Occasional microtag failure or loss was noted and fish death and/or tag loss were monitored daily throughout the experiment. The Specific Growth Rate (SGR) was calculated as: SGR (\% body mass per day) $=100$ (Ln $\left.\mathrm{BM}_{\mathrm{f}}-\mathrm{Ln} \mathrm{BM}_{\mathrm{i}}\right) \times \mathrm{t}^{-1}$, where $\mathrm{BMf}$ and $\mathrm{BMi}$ are the final and the initial body masses $(\mathrm{BM}, \mathrm{g})$ respectively, and $t$ the total number of days. To back-evaluate an early sex effect on growth, all fish from Exp. 2 were killed with an overdose of anesthetic at the end of experiment (at $289 \mathrm{dph}$ ) and phenotypic sex was determined according to the method described by Barnabé (1976). This method uses a macroscopic examination of gonads and defines 7 stages of gonad maturity. In the present experiment we observed stages 1 to 3 (with mainly stages 23): stage 1 corresponded to undetermined individuals when gonads are both threadlike; stage 2 corresponded to a $0.5 \mathrm{~cm}$ round ovary with a creamy color and no ovocytes could be distinguished, testes showed a typical triangular section and were transparent; finally stage 3 corresponded to a $1 \mathrm{~cm}$ granular round ovary with a creamy color and unseparated polyhedral ovocytes could be distinguished, testes color changed to pinkish grey. 


\subsection{Effect on swimming behavior (Exp. 2):}

Stress response to tagging processes is rarely systematically assessed. Measurement of post-tagging swimming performance can be used as a surrogate for a battery of physiological tests. To evaluate the possible effects of the tagging procedure on swimming behavior, fish from both groups (untagged controls and tagged fish) were therefore subjected to a specific test designed to measure their swimming activity over 3 hours with an exposure to a sudden dark challenge which represents a mildly stressful situation in which a novel stimulus triggers the expression of characteristic avoidance behaviors in several species (similar protocol to that of Benhaïm et al. 2013). The fish were allowed to acclimatise for $5 \mathrm{~min}$ before the start of video recording into the arenas setup composed of $12 \times 3$ I tanks (AquaBox® by Aqua Schwarz GmbH, Göttingen, Germany; $24.5 \times 15 \times 13.5 \mathrm{~cm}$ ), isolated from one another by opaque walls, filled with sea water, with each tank receiving a single fish. The arenas were filmed for $180 \mathrm{~min}$ : $120 \mathrm{~min}$ in the light, $15 \mathrm{~min}$ in darkness and then another $45 \mathrm{~min}$ in the light using Ethovision® XT tracking software (Noldus, The Netherlands). For the dark period, the light was turned off abruptly, resulting in sudden darkness, and then switched back on with a timer. The whole setup was placed on an infrared floor (IR floor $1 \times 1 \mathrm{~m}$, Noldus, The Netherlands) to avoid the reflection of light and to allow filming during dark periods.

Altogether, 72 fish (36 untagged controls, 36 tagged fish) were filmed at $105 \mathrm{dph}$ (at tagging day), 125 dph (21 days after) and 147 dph (42 days after); for $6 \times 3$ hours sessions each recorded: 6 untagged controls and 6 tagged fish. The same individuals ( 21 of the 36 tagged fish) were filmed at the three ages. The two variables of interest were distance travelled and angular velocity. For each individual, distance travelled was divided by fish body length (BL in $\mathrm{cm}$ ) to standardized values and avoid bias due to variation in fish size while angular velocity $\left({ }^{\circ} \mathrm{s}^{-1}\right)$ was used as an indicator of the trajectory (in terms of angle turned per time unit). Briefly, angular velocity is expressed in ${ }^{\circ} \mathrm{s}^{-1}$ and represents the angle turned in one second. A fish with a straight trajectory will have an angular velocity of $0^{\circ} \mathrm{s}^{-1}$ whereas a fish 
turning $90^{\circ}$ right then $60^{\circ}$ left in two seconds will have an angular velocity of $75^{\circ} \mathrm{s}^{-1}\left(150^{\circ}\right.$ in 2 seconds).

\subsection{Data Analyses:}

The data were analyzed for normality using the Shapiro-Wilk test, and for homoscedasticity using Bartlett's test. When normality and homoscedasticity were respected, t-tests and Repeated measures analysis of variance (RM-ANOVA) were performed. In case of nonnormality and/or non-homoscedasticity after log or square root transformation, the MannWhitney-U tests were used (see details for each experiment hereafter).

For Exp. 1, mass and SGR of tagged fish and untagged controls were compared using Student's t-test and survival analysis was conducted using Log-rank Mantel-Cox test.

For Exp. 2, to take into account the variability in fish size at $105 \mathrm{dph}$ and to determine the ideal fish size at tagging, the tagged fish were divided into ten classes (in $\mathrm{mg}$ ) for statistical analyses, i.e. [100; 200[; [200; 300[; [300; 400[; [400; 500[; [500; 600[; [600; 700[; [700; 800[; [800; 900[; [900; 1000[; [1000; >1100[. Mass, length and SGR values were compared using RM-ANOVA with mass classes at tagging used as a fixed factor (note that lengths were not available for the controls before $125 \mathrm{dph}$ ). Survival rates of untagged controls and tagged fish were compared using the Log-rank Mantel-Cox test.

For the swimming behavior study, distance travelled and angular velocity were summed or averaged respectively per 15 minutes. For the statistical analyses, the 3 hours sessions were divided into 12 periods of 15 minutes ( 1 to 12 ) to allow comparison of fish swimming activity levels and angular velocity per period between tagged fish and untagged controls. RMANOVA was used to compare distance travelled and angular velocity between treatment tagged and untagged control) with periods as fixed factors to take into account time dependence between periods followed by Newman-Keuls post-hoc tests. For the tagged fish, we were able to reassign the sex of 21 fish at $105 \mathrm{dph}, 23$ fish at $125 \mathrm{dph}$, and 25 fish at $147 \mathrm{dph}$ (out of 36), and the effect of sex on distance travelled and angular velocity variables was analyzed using RM-ANOVA with periods and sex as fixed factors. Two fish (one tagged 
and one untagged control) were removed from the behavioral analyses at $105 \mathrm{dph}$ due to abnormal values (detection problem during recording). Fish from both groups (tagged and untagged control) were tested for homogeneity of mass and body length using the MannWhitney test before comparing their swimming behavior.

For all tests, the significant threshold was $p<0.05$ and analyses were performed using $R^{\mathrm{TM}}$ freeware (http://www.r-project.org; http://cran.r-project.org) and Statistica® (Statsoft, Tulsa, OK, USA).

\section{Results}

\subsection{Survival, growth, tag retention \& early sex-related differences:}

\section{Experiment 1}

The initial body mass of the tagged $(840 \pm 20 \mathrm{mg}$, min-max $497-1260 \mathrm{mg})$ and untagged control fish (1010 mg $\pm 30 \mathrm{mg}$, min-max $463-1630 \mathrm{mg}$ ) was significantly different (t-test, $p<0.001$, Table 1) but this difference was due to the fact control fish were actually weighed and measured 5 days later (at $101 \mathrm{dph}$ ) for technical reason. For the rest of the experiment, no growth differences were found between untagged controls and tagged fish. The initial tag to body mass ratio was $2.2 \%$ for the smallest tagged fish and $0.96 \%$ for the heavier one. Tag reading failure was $10 \%$ between $96 \mathrm{dph}$ and $122 \mathrm{dph}$ (Table 1). Only four fish died on the day of tagging and were excluded from downstream analyses since their death were due to the lack of practice of the surgeon. No differences in survival rate were observed between tagged and untagged fish (96\% each) and survival curves were identical $\left(\mathrm{Chi}^{2}=0.023\right.$, $p=0.878)$.

\section{Experiment 2}

In this experiment, the initial tag to body mass ratio ranged from $0.65 \%$ to $4.01 \%$. For the tagged fish, mean survival rate over 6 months was $69 \%$ and ranged from $45.0 \%$ to $87.5 \%$ according to the initial body mass of the fish. A significant effect of body mass at tagging on survival rate was observed $\left(F_{(9,188)}=28.37, p<0.001\right)$ : the highest survival rate was found for the $[1000 ;>1100[$ class (Table 2 ). The threshold value of $73.7 \%$ survival was for the size 
class $400-500 \mathrm{mg}$ body mass at tagging along with a $78.9 \%$ microtag reading success for this size class at $169 \mathrm{dph}$ when fish mean body mass was $11.7 \mathrm{~g}$ (Table 2). Overall fish, microtag reading success was between $67.2 \%$ (lowest value observed at $197 \mathrm{dph}$ ) and 100\% observed at 105, 226, 273 and $289 \mathrm{dph}$; intermediates values were $85.9 \%$ at $125 \mathrm{dph}, 97.9 \%$ at $147 \mathrm{dph}$ and depending on class sizes between $42.9-88.9 \%$ at $169 \mathrm{dph}$. Tag loss was difficult to distinguish from reading failure and from fish death because it was difficult to find the tags in the large tank. Most fish mortality however occurred only during 15 days after tag insertion (Table 3 ) with a peak at 5 days post-tagging. The mortality rate was significantly lower in the control group compared to the tagged group, mostly from $105 \mathrm{dph}$ to $147 \mathrm{dph}$ $\left(\mathrm{Chi}^{2}=30.79, \mathrm{p}<0.001\right.$, Table 3$)$, but no differences in body mass were observed between the tagged fish and the controls (between $105 \mathrm{dph}$ and $289 \mathrm{dph}$, RM-ANOVA; $F_{(7,286)}=0.945, p=0.47$; Figure $\left.1 A\right)$ at any of the biometric measurement points. Similarly, no differences were observed between tagged and untagged controls fish for body length (between $147 \mathrm{dph}$ and $289 \mathrm{dph}$, RM-ANOVA $\left.\mathrm{F}_{(6,304)}=0.700 ; \mathrm{p}=0.65\right)$ or for SGR (RMANOVA; $\left.F_{(6,286)}=0.610 ; p=0.72\right)$. For tagged fish only, no SGR difference was found in relation to body mass class at tagging $\left(\mathrm{RM}-\operatorname{ANOVA~}_{(54,468)}=1.26, \mathrm{p}=0.10\right)$. When fish were euthanized for sex determination, microtags were retrieved in the body cavity either embedded in fat tissue or free. No inflammation was observed.

Concerning sexual dimorphism, mass differences were observed between males and females $\left(\right.$ RM-ANOVA $\left.F_{(16,192)}=3.64 ; p<0.001\right)$ at each biometric measurement time (Figure 1B), but no SGR differences $\left(\right.$ RM-ANOVA $\left.F_{(14,194)}=0.845 ; p=0.62\right)$. Retrospectively, we estimated that at $105 \mathrm{dph}\left(1024\right.$ degree days above $\left.10^{\circ} \mathrm{C}\right)$, the females were already $31 \%$ heavier than males in this population. This difference increased with time, reaching a maximum value of $44 \%$ and then stabilizing at around $40 \%$ after 197 dph (3048 degree days above $10^{\circ} \mathrm{C}$, Figure $1 \mathrm{C}$ ). 
For each behavioral test, fish from both groups (tagged and untagged) were tested to evaluate differences in mass and length using the Mann-Whitney test and no differences were found at any of the sessions. At $105 \mathrm{dph}$, when the fish were $590 \pm 220 \mathrm{mg}$ in mean mass and $38.5 \pm 5 \mathrm{~mm}$ in mean total length, total distances travelled per 15 -min period were compared (Figure 2A), the mean distance travelled for all individuals was

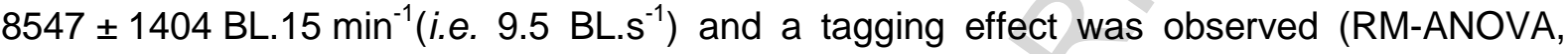
$\left.F_{(12,57)}=2.77, p=0.005\right)$ : the tagged fish swam more than the controls during the first 45 minutes post-surgery (Period 1 to Period 3 ). After this period, and during the light/dark challenge, no further differences in distance travelled were observed between the tagged and control fish, but both groups showed a slight increase in activity during the dark period. A treatment effect was also found for angular velocity (data not shown, range for tagged fish $\left[364.93-671.53^{\circ} . \mathrm{s}^{-1}\right]$, mean \pm SEM $504.55 \pm 109.54^{\circ} . \mathrm{s}^{-1}$; and for untagged controls $\left[566.65-615.99^{\circ} . \mathrm{s}^{-1}\right], \quad$ mean \pm SEM $566.65 \pm 25.02^{\circ} . \mathrm{s}^{-1} ; \quad$ RM-ANOVA $\left.F_{(12,} \quad 57\right)=2.76$, $p=0.005)$ : the tagged fish presented a lower angular velocity during the first five 15 -min periods (Period 1 to Period 5), i.e.75 min after being placed in the observation tank. After this session, no further differences in angular velocity were observed.

At $125 \mathrm{dph}, 21$ days after tagging, total distances travelled per 15-min period were compared (Figure 2B) with fish mean mass equal to $2490 \pm 860 \mathrm{mg}$ and mean total length equal to $61.3 \pm 6.8 \mathrm{~mm}$. Differences were observed (RM-ANOVA, $\left.F_{(12,59)}=2.44, p=0.012\right)$ : the tagged fish swam less than the controls during the first seven 15-min periods (Period 1 to Period 7, except during Period 5), i.e. for 105 min after being placed in the observation tanks. After this acclimatization period and during the light/dark challenge, no further differences were observed. The mean distance travelled for all individuals was $4466 \pm 847 \mathrm{BL} .15 \mathrm{~min}^{-1}$ (i.e. $4.9 \mathrm{BL} . \mathrm{s}^{-1}$ ), i.e. two times less than during the first session.

At 147 dph, 42 days after tagging, no difference was observed between tagged and control fish for any of the periods, for distance travelled and angular velocity, respectively (then, the mean mass of the fish was $7780 \pm 2530 \mathrm{mg}$ and mean total length was $88 \pm 9.3 \mathrm{~mm}$ ). The 
mean distance travelled for all individuals was $3913 \pm 282 \mathrm{BL} .15 \mathrm{~min}^{-1}$ (i.e. $4.3 \mathrm{BL} . \mathrm{s}^{-1}$ ), like at 125 dph.

No sex effect was found for distance travelled at $105 \mathrm{dph}, 125 \mathrm{dph}$ and $147 \mathrm{dph}$ (RM ANOVA: $F_{(12,7)}=0.105 ; p=0.466 ; F_{(12,12)}=1.592 ; p=0.216 ; F_{(12,10)}=0.363 ; p=0.950$, respectively).

\section{Discussion}

The options of researchers are limited for the identification and monitoring of small-bodied fish. External tagging with painting or visible alpha numeric tags proves difficult when large numbers of fish are used as is necessary in a selective breeding program, for example. The same applies to behavioral experiments where external tagging could influence social interactions. Internal electronic tagging is the ideal solution but so far, the method has been limited to fish above $60 \mathrm{~mm}$ in length and $1670 \mathrm{mg}$ in mass (Baras et. al., 2000), or with a fork length of $57 \mathrm{~mm}$ (Acolas et al., 2007). Technological developments and tag miniaturization have only very recently enabled fish to be followed from a very early stage of their life cycle using intra-coelomic implantation of glass microtags, as described by Cousin et al. (2012) and in this paper.

The microtags used in this study were very effective for the tagging and identification of small juveniles from $400 \mathrm{mg}$ in mass and $36 \mathrm{~mm}$ in standard length, enabling them to be followed throughout their growth. For fish weighing a mean of $600-800 \mathrm{mg}$, survival rates of $78.6 \%$ can be expected about one month after tagging with no effect on body mass and SGR, which is comparable to the results obtained on Salmo trutta by Acolas et. al. (2007) or on nonsalmonids by Ficke et al. (2011), although both in a larger size range (15-20 g). Fish in the mass class $400-500 \mathrm{mg}$ had a $73.7 \%$ survival rate, while those weighing less than $400 \mathrm{mg}$ were more affected, probably because tag insertion was proportionally more traumatic for them since their coelomic cavity is shorter. Nevertheless, even if the survival rate for the last mass class was low (50\%) in this experiment, the method allowed tagging of fish with a total 
length of $27 \mathrm{~mm}$ and a body mass of $197 \mathrm{mg}$. We however recommend using this method for microtagging fish from $400 \mathrm{mg}$ and $36 \mathrm{~mm}$ in total length.

This study also established that the early growth trajectory of the fish was significantly different for males and females as from 105 days (1024 degree days above $10^{\circ} \mathrm{C}$ ) with a $31 \%$ difference in mass in favor of the females. The differential growth in body mass was even reinforced over time until the end of our experiment, reaching $44 \%$ in 289 day-old fish, i.e. 9-10 months. These findings are consistent with earlier observations (Saillant et al. 2001, Coban et al. 2011) showing sexual mass dimorphism in favor of females in sea bass species. However, the previous works started longitudinal growth monitoring at 10 months of age and indicated a $67 \%$ mass gain (Saillant et al. 2001). They also showed that the size advantage of females subsequently decreased during the second growing season to stabilize at around $20-30 \%$. The present experiment hereby confirms that growth difference is mainly due to phenotypic sex, and that it occurs much earlier than previously concluded (Saillant et al. 2001).

Most studies investigating tagging effects monitor only growth and mortality whereas behavior is an integrative component reflecting adaptability to the tagging procedure. The number of publications on behavioral studies has increased in the past decade, and a suitable means of tagging is required to follow fish behavior. One requirement is that tag application should be associated with minimal or no stress to the fish, so the need for careful and systematic evaluation of tagging effects is essential (Bridger and Booth, 2003). The tag must not affect spontaneous behavior or increase vulnerability to predators when dealing with wild fish. In our study, distances travelled and angular velocities were monitored and revealed some behavioral differences in baseline activities between tagged fish and untagged controls just after tagging: tagged fish showed higher transient (45 min) swimming activity than the untagged controls; the hyperactivity could be specifically due to the surgery process and added tag mass since handling and anesthesia were also applied to the controls. After a short acclimatisation period, no further differences were observed between 
the two groups of fish, even during the light/dark changes which did not elicit differential responses according to fish treatment as one would expect in the case of a serious affect. These results are consistent with those of a previous study that investigated the effects of tagging on the swimming activity of lake whitefish (Coregonus clupeaformis), and which showed that handling, attachment surgery and tag presence did not seem to critically affect swimming activity levels (Bégout Anras et al., 1998). Similar conclusions were reached with sea bream (Sparus aurata), although transient higher cortisol levels were observed in tagged fish (Montoya et al. 2012). The sea bass reacted to the photo motor challenge with hyperactivity, but both groups showed the same ability to recover from the sudden dark challenge, resuming earlier activity levels within the following period. Angular velocity differed between the groups just after tagging and was characterized by lower mean values in tagged fish. This corresponded to circular trajectories, illustrating stereotypic behavior (abnormal repetitive behavior with no apparent goal or function, Garner 2005; Turner 1997), and likely reflecting anxiety of tagged fish just after tagging. At 21 days post-tagging, tagged fish showed less activity for $1 \mathrm{~h} 45 \mathrm{~min}$ after the start of the behavioral test. The reason why tagged fish showed lower activity than untagged fish only at the beginning of the second behavioral test is not clear. Persistence of a tagging effect should have led the fish to demonstrate higher activity (Bégout Anras et al, 1998) throughout the experiment and particularly during the stress period. Furthermore, it is interesting to note that activity levels decreased significantly and was divided by two between the initial session and 21 days later. This could either reflect the acclimatization of the fish to the observation tanks or be a consequence of the relative size of the fish to the size of the observation tanks, or a combination of both factors. Both body size and age (previous experience) could influence activity, but also the response to the transfer in the behavior observation tanks. Such an arena size effect was noted during similar tests conducted with zebrafish larvae (Padilla et al., 2011) which showed that the higher swimming activity was observed in the larger arena. At 42 days post-tagging, no differences were found in any variables of interest. 
In conclusion, these results highlight the need of an acclimatization period ( 21 to 42 days) for small sea bass juveniles to fully recover from intra-coelomic tagging, and this is also required before the carrying out of behavioral tests to avoid bias. Similar conclusions were reached with small-bodied zebra fish at two months post-tagging (Cousin et al. 2012).

This study is the first to our knowledge to report the effects of tagging on growth and behavior on juvenile seabass from the smallest size class mean mass of $170 \pm 30 \mathrm{mg}$ (150 $197 \mathrm{mg})$ and mean length of $32.5 \pm 7.8 \mathrm{~mm}(27-38 \mathrm{~mm})$ and for such an early and long time (184 days, starting at $105 \mathrm{dph}$ ). It is also the first to show such early, individual sexrelated body mass differences. Using this tagging method, we showed that sea bass females were $31 \%$ heavier than males as from 105 days. Further research is needed to uncover the mechanisms responsible for these differences. The micro-tagging method could be further developed to improve the non-invasive longitudinal monitoring of individual traits. The method could be used in behavioral studies, which must be carried out from as young as possible to characterize individual variability and consistency in behavior, or it could be used to identify productivity traits which could help selection programs and greatly reduce hatchery costs by fish being screened for different traits as early as $105 \mathrm{dpf}$ for sea bass (400-500 mg) and by developing further common garden experiments.

\section{Acknowledgments}

The research leading to these results received funding from the European Union Seventh Framework Program (FP7/2007-2013) under grant agreement No. 262336, AQUAEXCEL. The authors gratefully acknowledge the funding of this work by the European Union and by the county council of Charente Maritime (PhD grant to SF).

\section{References}


Acolas, M.L., Roussel, J.M., Lebel, J.M., Baglinière, J.L., 2007. Laboratory experiment on survival, growth and tag retention following PIT injection into the body cavity of juvenile brown trout (Salmo trutta). Fisheries Research 86, 280-284.

Ali, S, Champagne, D., Richardson, M.K., 2012. Behavioral profiling of zebrafish embryos exposed to a panel of 60 water-soluble compounds. Behav. Brain Res. 228, 272-283.

Armstrong, J.D., Braithwaite, V.A., Rycroft, P., 1996. A flat-bed passive integrated transponder antennae array for monitoring behaviour of Atlantic salmon parr and other fish. J. Fish Biol. 48, 539-541.

Baras, E., Westerloppe, L., Mélard, C., Philippart, J.C., Bénech, V., 1999. Evaluation of implantation procedures for PIT-Tagging juvenile Nile tilapia. North American Journal of Aquaculture 61, 246-251.

Baras, E., Malbrouck, C., Houbart, M., Kestemont, P., Mélard, C., 2000. The effect of PIT tags on growth and physiology of age-0 cultured Eurasian perch Perca fluviatilis of variable size. Aquaculture 185, 159-173.

Barnabé, G., 1976. Contribution à la connaissance de la biologie du loup, Dicentrarchus labrax (L.) (Poisson Serranidae). Thèse de Doctorat d'état, mention Sciences, Université des Sciences et Techniques du Languedoc, Montpellier, 426p.

Bégout Anras, M.-L., Bodaly, R.A., McNicol, R.E., 1998. Use of an acoustic beam actograph to assess the effects of external tagging procedure on lake whitefish swimming activity. Transactions of the American Fisheries Society, 127, 329-335.

Bégout, M.-L., Kadri, S., Huntingford, F. Damsgård, B., 2012. Techniques for studying the behaviour of farmed fish. In Aquaculture and Behavior (ed. F. Huntingford, M. Jobling and S. Kadri), pp. 65-86. Chichester: John Wiley and Sons Ltd.

Bergensen, E. P., Rogers, K. B., Conger L.V., 1994. A livestock hormone pellet injector for implanting PIT tags. North American Journal of Fisheries Management 14, 224-225. 
Benhaïm, D., Guyomard, R., Chatain, B., Quillet, E., Bégout, M-L., 2013. Genetic differences for behaviour in juveniles from two strains of brown trout suggest an effect of domestication history. Applied Animal Behaviour Sciences 147, 235-242.

Brannäs, E., Alanärä, A., 1993. Monitoring the demand feeding activity of individual fish with a demand feeding system. J. Fish Biology 42, 209-215.

Brannäs, E., Alanärä, A., 1994. Effect of reward level on individual variability in demand feeding activity and growth rate in Arctic charr and rainbow trout. Journal of Fish Biology 45, 423-434

Brennan, N. P., Leber, K. M., Blankenship, H. L., Ransier, J. M., DeBruler Jr, R. 2005. An evaluation of coded wire and elastomer tag performance in juvenile common snook under field and laboratory conditions. North American Journal of Fisheries Management 25, 437-445.

Bridger, C.J., Booth, R.K., 2003. The effects of biotelemetry transmitter presence and attachment procedures on fish physiology and behavior. Reviews in Fisheries Sciences 11, 13-34.

Champigneulle, A., Escomel, J., Laurent, P. 1987. Marquage d'ombles chevalier (Salvelinus alpinus) de petite taille par injection de micromarques magnétisées. Bulletin Français de la Pêche et de la Pisciculture 304, 22-31.

Chatain, B., 1994. Estimation et amélioration des performances zootechniques de l'élevage larvaire de Dicentrarchus labrax et de Sparus auratus. Thèse de Doctorat d'Etat, Univ. d'Aix-Marseille II 199 pp.

Çoban, D., Yildirim, Ş., Kamaci, H. O., Suzer, C., Saka, Ş., Firat, K., 2011. External morphology of European seabass (Dicentrarchus labrax) related to sexual dimorphism. Turkish Journal of Zoology 35, 255-263.

Cousin, X., Daouk, T., Péan, S., Lyphout, L., Schwartz, M.-E., Bégout, M.-L., 2012. Electronic individual identification of zebrafish using radio frequency identification (RFID) microtags. J. Exp. Biol. 215, 2729-2734. 
Decourtye, A., Devillers, J., Aupinel, P., Brun, F., Bagnis, C., Fourrier, J., Gauthier, M., 2011. Honeybee tracking with microchips: a new methodology to measure the effects of pesticides. Ecotoxicology 20, 429-437.

Ficke, A. D., Myrick, C. A., Kondratieff, M. C., 2011. The effects of PIT tagging on the swimming performance and survival of three nonsalmonid freshwater fishes." Ecological Engineering 48: 86-91.

Gibbons, J. W., Andrews, K. M., 2004. PIT tagging: simple technology at its best. BioScience, 54, 447-454.

Garner, JP., 2005. Perseveration and stereotypy-systems-level insights from clinical psychology. In: J Rushen, G Mason, eds. Stereotypic Animal Behaviour: Fundamentals and Applications to Welfare. 2nd ed. Wallingford UK: CAB International.

Laursen, D.C., Olsén, H. L., Ruiz-Gomez, M.d.L., Winberg, S., Höglund, E., 2011. Behavioural responses to hypoxia provide a non-invasive method for distinguishing between stress coping styles in fish. Applied Animal Behaviour Science 132, 211-216.

Millot, S., Bégout, M.L., Chatain, B., 2009. Risk-taking behaviour variation over time in sea bass Dicentrarchus labrax: effects of day-night alternation, fish phenotypic characteristics and selection for growth. J. Fish Biol. 75, 1733-1749.

Montoya, A., López-Olmeda, J. F., Lopez-Capel, A., Sánchez-Vázquez, F. J., Pérez-Ruzafa, A., 2012. Impact of a telemetry-transmitter implant on daily behavioral rhythms and physiological stress indicators in gilthead seabream (Sparus aurata). Marine Environmental Research79, 48-54.

Moreau, M., Arrufat, P., Latil, G., Jeanson, R., 2011. Use of radio-tagging to map spatial organization and social interactions in insects. J. Exp. Biol. 214, 17-21.

Navarro, A., Oliva, V., Zamorano, M.J., Gines, R., Izquierdo, M.S., Astorga, N., Afonso, J.M., 2006. Evaluation of PIT system as a method to tag fingerlings of gilthead seabream (Sparus auratus L.): Effects on growth, mortality and tag loss. Aquaculture 257, 309315. 
Ombredane, D., Baglinière, J.L., Marchand, F., 1998. The effects of passive integrated transponder tags on survival and growth of juvenile brown trout (Salmo trutta L.) and their use for studying movement in a small river. Hydrobiologia 371/372, 99-106.

Padilla, S, Hunter, DL, Padnos, B, Frady, S, MacPhail, R.C., 2011. Assessing locomotor activity in larval zebrafish: Influence of extrinsic and intrinsic variables. Neurotoxicology and Teratology 33, 624-30.

Peterson, N. P., Prentice,E. F., Quinn, T.P., 1994. Comparison of sequential coded wire and passive transponder tags for assessing overwinter growth and survival of juvenile coho salmon. North American Journal of Fisheries Management 14:870-873.

Piferrer, F., Blazquez,M., Navarro,L., Gonzalez, A., 2005 Genetic, endocrine, and environmental components of sex determination and differentiation in the European sea bass (Dicentrarchus labrax L.). Gen. Comp. Endocrinol. 142: 102-110.

Prentice, E. F., Park,D. L., Sims, C.W., 1984. A study to determine the biological feasibility of a new fish tagging system. Report (contract DEA179- 83BP1192, project 83-19) to Bonneville Power Administration, Portland, Oregon.

Prentice, E.F., Flagg, T.A., McCutcheon, C.S., Brastow, D.F., 1990a. PIT-Tag monitoring systems for hydroelectric dams and fish hatcheries. Am. Fish. Soc. Symp. 7, 323-334.

Prentice, E.F., Flagg, T.A., McCutcheon, C.S., 1990b. The effect of passive integrated transponder (PIT) tags in salmonids. Am. Fish. Soc. Symp. 7, 317-322.

Saillant, E., Fostier, A., Menu, B., Haffray, P., Chatain, B., 2001. Sexual growth dimorphism in sea bass, Dicentrarchus labrax. Aquaculture 202, 371-387.

Saillant, E., Fostier, A., Haffray, P., Menu, B., Laureau, S., Thimonier, J., Chatain, B., 2003. Effects of rearing density, size grading and parental factors on sex ratios of the sea bass (Dicentrarchus labrax L.) in intensive aquaculture. Aquaculture 221, 183-206.

Summerfelt, R.C., Smith, L.S., 1990. Anesthesia, surgery, and related techniques. Methods for fish biology: American Fisheries Society, Bethesda, Maryland, 213-272. 
Turner, M., 1997. Towards an executive dysfunction account of repetitive behaviour in autism. In: Russell J, ed. Autism As an Executive Disorder. New York: Oxford University Press. p 57-100.

Tveteras, R., Nystoyl, R., 2011. Fish production. Estimates \& Trends 2011-2012. CD Abstracts. Proceeding of Global Outlook for Aquaculture Leadership 2011, 6-9 Nov 2011. Santiago, Chile.

Vandeputte, M., Dupont-Nivet, M., Chavanne, H., Chatain, B., 2007. A polygenic hypothesis for sex determination in the European seabass Dicentrarchus labrax. Genetics. 176, 1049-1057.

Winter, J. D., 1983. Underwater biotelemetry. In Fisheries Techniques (ed. L. A. Nielsen and D. L. Johnson), pp. 371-395. Bethesda, MD: American Fisheries Society. 


\section{Figure legends}

Figure 1: A. Growth monitoring (body mass, mean \pm SD, in $\mathrm{g}$ ) of untagged controls (black symbol) and tagged fish (grey symbol) over 6 months in experiment 2. No differences were found for the entire duration of the experiment; $B$ - Comparison of body mass ( $g$, mean $\pm S D$ ) according to sex (black symbols $=$ females, grey symbol $=$ males) of tagged fish. $\mathrm{C}-$ Mass gain (\%) of females compared to males (\%).Significant differences are showed with * $(p<0.05)$

Figure 2: Comparison of total distances travelled (Body length per 15 min, mean \pm SEM) between untagged controls (black column) and tagged fish (grey column) for each 15-min period of the whole experiment (Period 1 to Period 12). A - at $105 \mathrm{dph}$, just after tagging; B at $125 \mathrm{dph}, 21$ days post-tagging and $\mathbf{C}$ - at $147 \mathrm{dph}, 42$ days post-tagging. Significant differences are showed with * $(p<0.05)$. Columns highlighted by grey surface in period 9 represent the dark period of behavioral test. 
Table 1: Comparison of body mass $(\mathrm{g})$, standard length $(\mathrm{mm})$, SGR, Tag to fish mass ratio, Tag loss and mortality rate (\%) between tagged and untagged controls fish in experiment 1 , (dph: days post hatching). Characters in bold indicate significant differences between tagged and untagged controls (t-test, $\alpha=0.05)$.

\begin{tabular}{|c|c|c|}
\hline & Tagged fish & Untagged \\
\hline Intitial number $(\mathrm{N})$ & 50 & 50 \\
\hline \multicolumn{3}{|l|}{ Body mass $(B M$, mean $\pm S D, g)$} \\
\hline $96 \mathrm{dph}$ & $0.84 \pm 0.02$ & - \\
\hline $101 \mathrm{dph}$ & $-C$ & $1.01 \pm 0.03$ \\
\hline 206 dph & $9.57 \pm 0.34$ & $10.10 \pm 0.33$ \\
\hline $258 \mathrm{dph}$ & $11.85 \pm 0.23$ & $12.99 \pm 0.22$ \\
\hline \multicolumn{3}{|c|}{ Standard length (SL, mean $\pm S D, m m)$} \\
\hline $96 \mathrm{dph}$ & $36.14 \pm 0.33$ & - \\
\hline $101 \mathrm{dph}$ & - & $38.08 \pm 0.41$ \\
\hline 206 dph & $82.05 \pm 0.92$ & $82.02 \pm 1.10$ \\
\hline $258 \mathrm{dph}$ & $87.29 \pm 0.15$ & $97.74 \pm 0.79$ \\
\hline \multicolumn{3}{|l|}{ Specific Growth Rate (mean, \%) } \\
\hline $96 \mathrm{dph}-122 \mathrm{dph}$ & 0.69 & 0.67 \\
\hline 206 dph - 258 dph & 2.36 & 2.45 \\
\hline \multicolumn{3}{|l|}{ Tag ratio (mean \% BM) } \\
\hline $96 \mathrm{dph}-122 \mathrm{dph}$ & 1.19 & - \\
\hline 122 dph - 143 dph & 0.50 & - \\
\hline 143 dph - 164 dph & 0.18 & - \\
\hline 164 dph - 206 dph & 0.15 & - \\
\hline 206 dph - 258 dph & 0.06 & - \\
\hline \multicolumn{3}{|c|}{ Tag loss and/or reading failure (\% of total number at last biometry) } \\
\hline $96 \mathrm{dph}-122 \mathrm{dph}$ & 10 & - \\
\hline 122 dph - 143 dph & 4 & - \\
\hline 143 dph - 164 dph & 2 & - \\
\hline 164 dph - 206 dph & 5 & - \\
\hline 206 dph - 258 dph & 0 & - \\
\hline \multicolumn{3}{|l|}{ Mortality (\%) } \\
\hline $258 \mathrm{dph}$ & 8 & 8 \\
\hline
\end{tabular}


Table 2: General table of fish number, body mass (BM, mg), tag to fish mass ratio (\%), survival rates (\%), tag reading rate at 169 dph (days post hatching), percentage of fish per sex (\%), percentage of undetermined sex (\%), and Specific Growth Rates between biometries (\% of BM.d ${ }^{1}$ ) according to sex of tagged fish and initial body mass classes at tagging in experiment 2.

\begin{tabular}{|c|c|c|c|c|c|c|c|c|c|c|c|c|c|c|c|c|}
\hline Mass Class (mg) & {$[100 ; 200[$} & {$[200 ; 300[$} & {$[300 ; 400[$} & \multicolumn{5}{|c|}{$[400 ; 500[[500 ; 600[\quad[600 ; 700[$} & \multicolumn{2}{|c|}{$[700 ; 800[$} & \multicolumn{2}{|c|}{$[800 ; 900[$} & \multicolumn{2}{|c|}{$[900 ; 1000[$} & \multicolumn{2}{|c|}{$[1000 ;>1100[$} \\
\hline Initial number (N) & 2 & 20 & 15 & 19 & & & \multicolumn{2}{|c|}{28} & \multicolumn{2}{|c|}{18} & \multicolumn{2}{|c|}{16} & \multicolumn{2}{|c|}{12} & \multicolumn{2}{|c|}{8} \\
\hline Mean BM (all sex, mg) & 175 & 262 & 347 & 456 & & 44 & \multicolumn{2}{|c|}{658} & \multicolumn{2}{|c|}{747} & \multicolumn{2}{|c|}{849} & \multicolumn{2}{|c|}{934} & \multicolumn{2}{|c|}{1080} \\
\hline Mean tag ratio (\% of BM) & 4.0 & 2.7 & 2.0 & 1.5 & 1 & 3 & \multicolumn{2}{|c|}{1.1} & \multicolumn{2}{|c|}{0.9} & \multicolumn{2}{|c|}{0.8} & \multicolumn{2}{|c|}{0.7} & \multicolumn{2}{|c|}{0.6} \\
\hline Survival rate (\% of total) & 50.0 & 45.0 & 46.7 & 73.7 & 76 & 5.0 & \multicolumn{2}{|c|}{78.6} & & 7.8 & 75 & 5.0 & 83 & & & 7.5 \\
\hline Reading rate at $169 \mathrm{dph}$ & 50.0 & 42.9 & 60.0 & 78.9 & 72 & 2.0 & & 5.7 & & 3.9 & 75 & 5.0 & 83 & .3 & & 7.5 \\
\hline Sex & $M \quad F$ & $M \quad F$ & $M \quad F$ & $M F$ & $M$ & $F$ & $M$ & $F$ & $\mathrm{M}$ & $\mathrm{F}$ & $\mathrm{M}$ & $\mathrm{F}$ & $\mathrm{M}$ & $F$ & $M$ & $F$ \\
\hline Percentage per sex & 0 & 88.911 .1 & $85.7 \quad 0.0$ & $71.4 \quad 14.3$ & 52.6 & 44.7 & 31.8 & 68.2 & 35.7 & 50.0 & 16.7 & 83.3 & 50.0 & 50.0 & 14.3 & 85.7 \\
\hline $\begin{array}{l}\text { Percentage undetermined } \\
\text { Specific Growth Rate }\end{array}$ & 100.0 & 0.0 & 14.3 & 14.3 & 2 & 6 & & .0 & & 4.3 & 0 & .0 & 0 & & & .0 \\
\hline $105 d p h-125 d p h$ & 7.2 & $7.6 \quad 11.4$ & 7.5 & 7.7 & 6.9 & 7.2 & 6.4 & 7.0 & 5.2 & 6.6 & 4.6 & 6.7 & 5.9 & 6.4 & 7.2 & 6.5 \\
\hline $105 d p h-289 d p h$ & 2.8 & $2.9 \quad 3.3$ & 2.9 & 2.9 & 2.6 & 2.8 & 2.6 & 2.7 & 2.6 & 2.6 & 2.3 & 2.6 & 2.5 & 2.6 & 2.6 & 2.6 \\
\hline
\end{tabular}


Table 3: Number of dead fish and mortality rates (\%) of the total number of tagged and untagged control fish between each biometric measurements for experiment 2 .

\begin{tabular}{ccc}
\cline { 2 - 3 } & Tagged & Untagged control \\
\hline Initial number & 188 & 201 \\
\hline Interval between biometry & & 0 \\
\hline $105 \mathrm{dph}-125 \mathrm{dph}$ & $35(18.6 \%)$ & 0 \\
$125 \mathrm{dph}-147 \mathrm{dph}$ & $4(2.1 \%)$ & 0 \\
$147 \mathrm{dph}-169 \mathrm{dph}$ & $6(3.2 \%)$ & $11(5.6 \%)$ \\
$169 \mathrm{dph}-197 \mathrm{dph}$ & $5(2.7 \%)$ & $1(0.5 \%)$ \\
$197 \mathrm{dph}-226 \mathrm{dph}$ & $1(0.5 \%)$ & $4(2.1 \%)$ \\
$226 \mathrm{dph}-273 \mathrm{dph}$ & $3(1.6 \%)$ & 0 \\
$273 \mathrm{dph}-289 \mathrm{dph}$ & 0 & 16 \\
\hline Total mortality (Running sum) & 54 & 0 \\
\hline
\end{tabular}




\section{Figure 1}
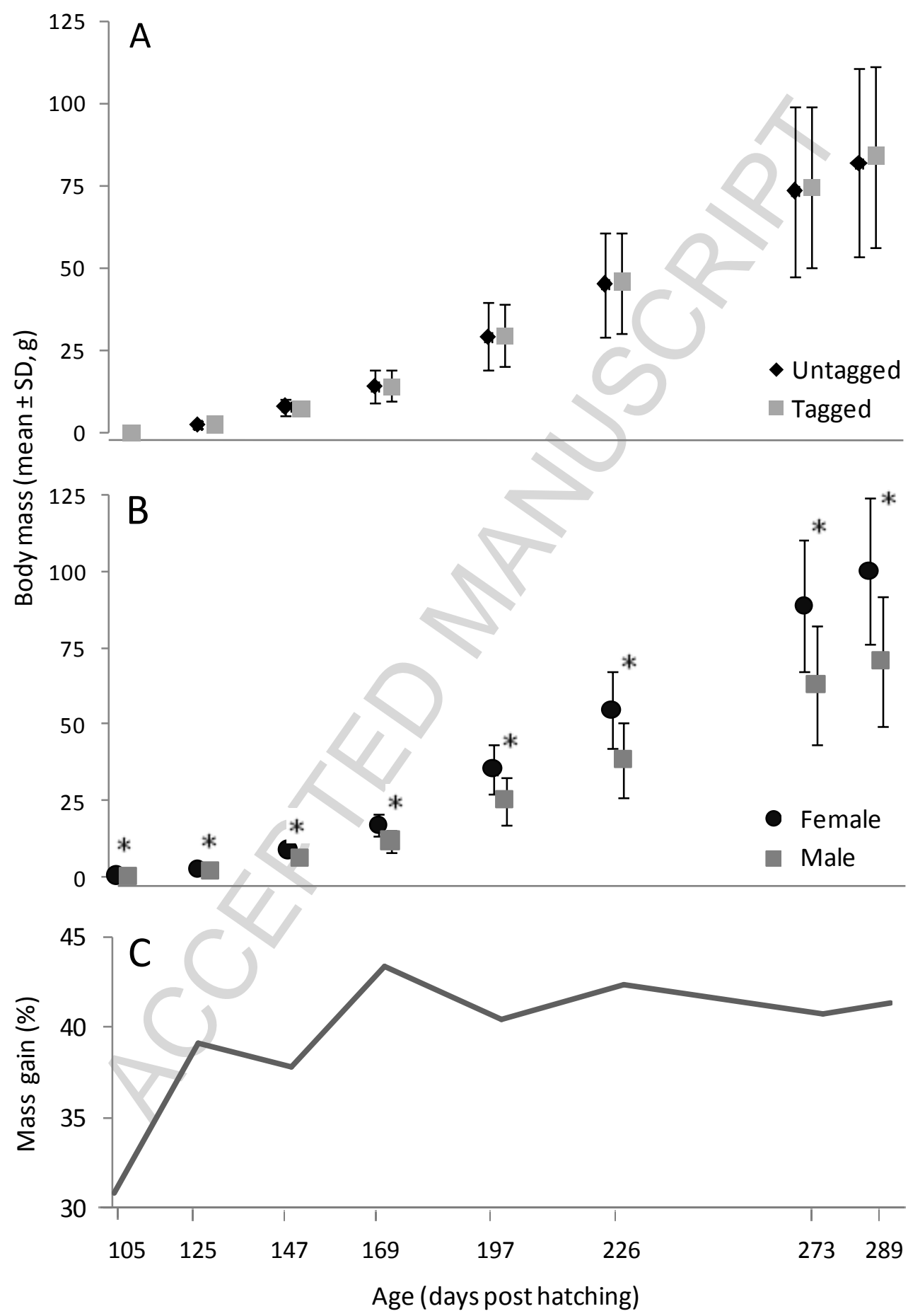
Figure 2

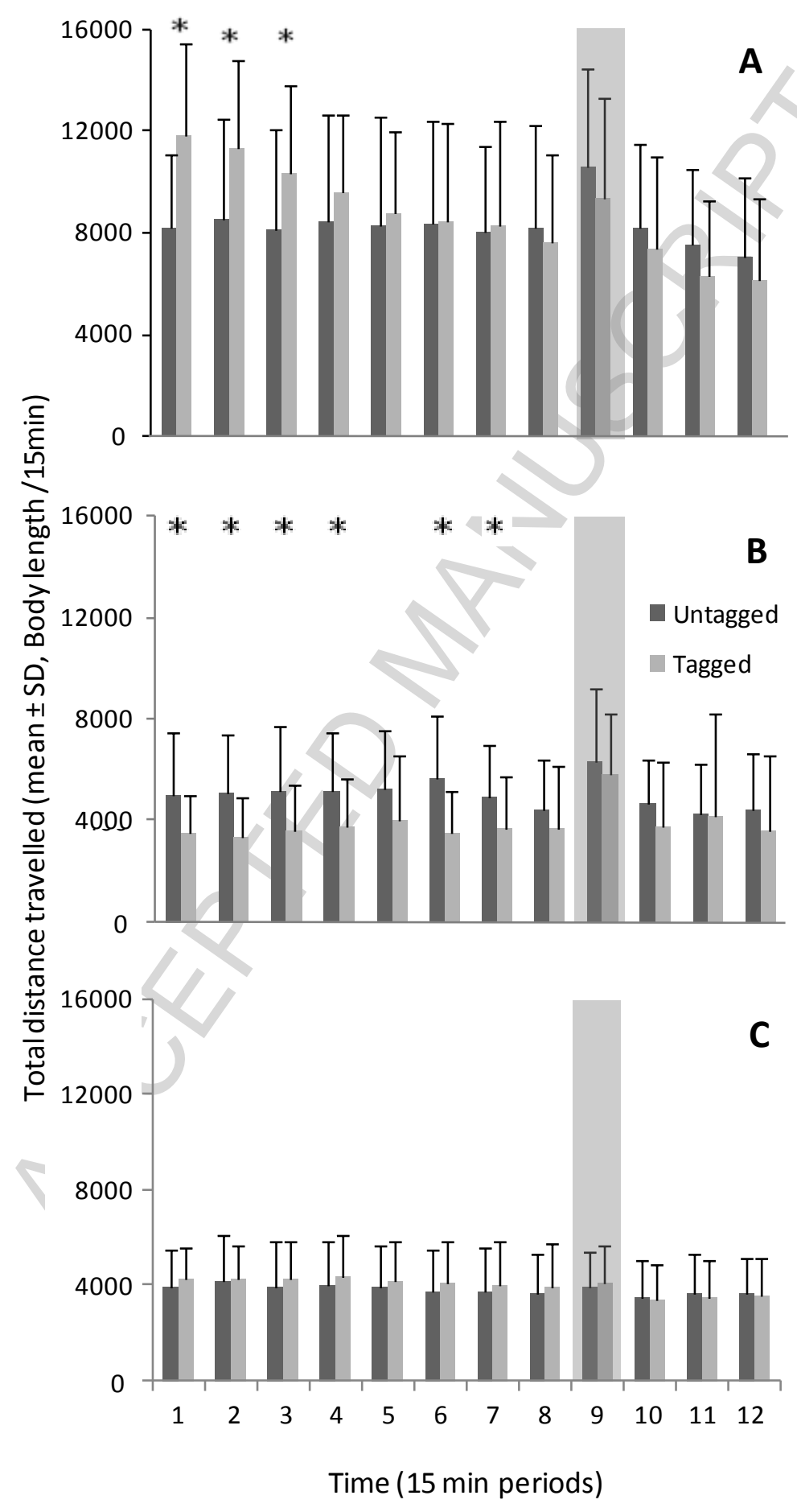


Highlights

- RFID microtagging of 105 day-old sea bass weighing between 200 - $1000 \mathrm{mg}$ does not alter growth

- Behavior return to normal responses between 4 and 6 weeks

- Sex-related mass gain (+31\% for females) demonstrated as early as 105 days 